No. 4619 May 10,1958

The standing waves described in this communication are different from the well-known stationary striations which can form in molecular gases passing smaller currents; the latter have a different shape and electrical properties ${ }^{5}$, and, it is believed, can occur without oscillation ${ }^{6}$.

We wish to thank Prof. N. L. Oleson for his interest in this work.

Department of Physics,

The Queen's University,

Belfast.

March 6.

* Present address: United States Naval Postgraduate School, Monterey, California.

${ }^{1}$ See Pigg, M. K., Burton, J. B., and Oleson, N. L., Proc. Third Internat. Conf. Ionization Phenomena in Gases, 833 (Venice 1957). Emeléus, $K_{\text {. }} G_{\text {, }}$ and Love, B., ibid., p. 289.' Pilon, A. M. Phys. Rev., 107, 25 (1957)

${ }^{2}$ Aston, F. W., and Kikuchi, T., Proc. Roy. Soc., A, 98, 51 (1921).

${ }^{3}$ Oleson, N. L., and Cooper, A. W. M., Phys. Rev., 105, 1411 (1957).

${ }^{4}$ Takamine, T., Suga, T., and Yanagihara, A., Scientific Papers, Inst: Phys and Chem. Res., Tokyo, No, 403 (1933).

${ }^{5}$ ef. Boyd, R. L. F., and Twiddy, N. D., Nature, 173, 633 (1954). ' Emeléus, K. G., Love, B., and Witherspoon, A. E., J. Electronics,
1, 559 (1956).

\section{Effect of Pressure on Burning Velocity of Nitric Oxide Flames}

THE burning velocities of stoichiometric mixtures of hydrogen and nitric oxide, and of methane and nitric oxide have been measured by the Bunsen burner method over the pressure-range $0 \cdot 2-40$ atm. abs. An averaged burning velocity was obtained from the measurement of the total volume flow of gas and the total area of the flame front. The experimental technique was essentially that of Diederichsen and Wolfhard ${ }^{1}$.

Measurements were made at a constant Reynolds number ${ }^{1,2}$ for each of the hydrogen and methane systems. Moreover, the diameter of the burner was varied approximately inversely as the pressure, so as to maintain as nearly as possible the same flameshape at all pressures. In this way the relative contributions of those parts of the Bunsen-type flame, which are recognized to be respectively greater or less than the mean value of the burning velocity, can be kept constant. The measurements should then give a true indication of the dependence of the burning velocity upon pressure.

The results obtained in this investigation are recorded in Table 1, and indicate that burning velocity is independent of pressure within the limits of experimental error in the range 1-40 atm. The value of the burning velocity of the hydrogen/nitric oxide flame at atmospheric pressure is substantially greater than those reported in the literature, namely, $30 \mathrm{~cm}$. $/$ sec. (ref. 3) and $22 \mathrm{~cm}$. $/ \mathrm{sec}$. (ref. 4). The lack of a significant dependence on pressure in the results of this investigation is at variance with the findings of Rozlovskii, ${ }^{4}$, who reports that the burning velocity of a nearly stoichiometric hydrogen/nitric oxide flame is independent of pressure in the range 1.8-4 atm. abs., but increases with pressure $p$ according to a $p^{0.482}$ law for $p$ between 4 and 19 atm. abs.

The hydrogen/nitric oxide and methane/nitric oxide systems may be compared with the methane/ oxygen system discussed by Diederichsen and Wolfhard ${ }^{1}$. In each case the flame temperature varies
Table 1

\begin{tabular}{|c|c|c|c|}
\hline \multicolumn{2}{|c|}{ Hydrogen-nitric oxide } & \multicolumn{2}{c|}{ Methane-nitric oxide } \\
\hline $\begin{array}{c}\text { Pressure } \\
\text { (atm. abs.) }\end{array}$ & $\begin{array}{c}\text { Burning velocity } \\
\text { (cm./sec.) }\end{array}$ & $\begin{array}{c}\text { Pressure } \\
\text { (atm. abs.) }\end{array}$ & $\begin{array}{c}\text { Burning velocity } \\
\text { (cm./sec.) }\end{array}$ \\
\hline 0.32 & 36 & $0 \cdot 23$ & 29 \\
1.00 & 49 & 0.98 & 41 \\
$3 \cdot 0$ & 63 & $3 \cdot 0$ & 42 \\
$6 \cdot 1$ & 63 & $6 \cdot 5$ & 42 \\
9.8 & 63 & 13.9 & 37 \\
10.5 & 60 & 27.6 & 34 \\
21.4 & 54 & & \\
29.9 & 53 & & \\
40.5 & 60 & & \\
\hline
\end{tabular}

markedly with pressure whereas the concentrations of hydroxyl radicals, and hydrogen and oxygen atoms, vary only slightly with pressure. None of these systems shows a significant variation of burning velocity with pressure.

It has been suggested ${ }^{5}$ that the mechanism of the hydrogen/nitric oxide flame differs from that of the methane/nitric oxide flame and is, in fact, governed by the bimolecular decomposition of nitric oxide as the rate-determining step. However, such a proposed difference in mechanism is not reflected by any significant difference in the dependence on pressure or magnitude of the burning velocity of the hydrogen/ nitric oxide flame as compared to the methane/nitric oxide flame.

\section{G. A. McD, Cummings}

Royal Aircraft Establishment

(Ministry of Supply),

Westcott, Bucks.

March 13.

${ }^{1}$ Diederichsen, J., and Wolfhard, H. G., Trans. Farad. Soc., 52, 1 (1956).

Wohl, K., "AGARD Selected Combustion Problems", 2, comment on p. 36i' (Butterworths, 1956).

${ }^{3}$ Parker, W. G. , and Wolfhard, H. G., Proc. 4th Symp. on Combustion, 420 (Williams and Wilkins Co., 1953).

4 Rozlovskii, A. I., Zhur. Fiz. Khim., 30,912 (1956). Murray, R. C., R.A.E. Library Translation No. 656 .

${ }^{5}$ Adams, G. K., Parker, W. G., and Wolfhard, H. G., Disc. Farad. Soc, 14, 97 (1953). Wolfhard, H. G., and Parker, W. G., Proc. Chapman and Hall, Ltd., London, 1955).

\section{Role of Photons in Argon-Alcohol Counters}

Ir is well known that in a Geiger discharge some of the avalanche photons, presumably argon resonance photons $^{1}$, are strongly absorbed in the quenching gas and are responsible for the discharge propagation in a narrow zone around the anode ${ }^{2}$. On the other hand photons of greater wave-length are also produced; these can release photo-electrons out of the cathode with subsequent production of secondary avalanches ${ }^{3,4}$. Some authors ascribe a dominant role in the discharge-spreading mechanism to the latter photons. In this assumption the velocity of discharge propagation would be determined by the photo-electric effect at the cathode and not by the photo-ionization of the gas near the anode, as is usually admitted. This contradicts the following experiment.

We used the counter sketched in Fig. 1. It has three aluminium cathodes $A, B$ and $C$, diameter $1.5 \mathrm{~cm}$., with lengths $3 \mathrm{~cm}$., $10 \mathrm{~cm}$. and $3 \mathrm{~cm}$. respectively, held at a mutual distance of $0.2 \mathrm{~mm}$. by suitable glass tubes. The anode is a central molybdenum wire, diameter $0.08 \mathrm{~mm}$. Cathode $A$ has a mica window $\left(3 \mathrm{mgm} . / \mathrm{cm} .{ }^{2}\right)$. The filling gas is argon (9 cm. mercury) and alcohol vapour (1 cm. mercury). 